\title{
Voluntary warnings and the limits of good prescribing behavior: the case for de-adoption of meperidine
}

This article was published in the following Dove Press journal:

Journal of Pain Research

15 December 2015

Number of times this article has been viewed

\section{Kevin J Friesen \\ Jamie Falk \\ Shawn Bugden}

College of Pharmacy, Faculty of Health Sciences, University of Manitoba, Winnipeg, MB, Canada
Correspondence: Shawn Bugden College of Pharmacy, Faculty of Health Sciences, University of Manitoba, 750 McDermot Avenue, Winnipeg, MB R3E 0T5, Canada

Tel +l 2048039093

Fax +I 8777768332

Email shawn.bugden@umanitoba.ca
Background: Meperidine (pethidine) offers little to no therapeutic advantage over other opioids, may be more prone to abuse, and produces a neurotoxic metabolite with a long half-life. The Institute for Safe Medication Practices (ISMP) issued warnings in 2004 and 2005 suggesting that meperidine be avoided, and when used, it should be in limited doses $(<600 \mathrm{mg} / 24 \mathrm{~h})$ and for a limited duration ( $<48$ hours). Hospitals have responded to these warnings, but much less is known about meperidine prescribing in the community setting. This study examined the potential impact of ISMP warnings on the prescribing of meperidine using time series analysis.

Methods: A population-based longitudinal cross-sectional study was conducted to examine oral meperidine utilization among persons 16 years of age and older in Manitoba, Canada, between April 1, 2001 and March 31, 2014. Amounts of meperidine were expressed using defined daily doses (DDDs), the equivalent of $400 \mathrm{mg}$ of meperidine per day. The number of meperidine prescriptions and users per quarter were determined and analyzed using regression analysis.

Results: There were 49,063 prescriptions for 442,641 DDDs of meperidine dispensed to 9,374 distinct users. The number of DDDs of meperidine per 1,000 persons peaked in the second quarter of 2003 at 11.75 , and then dropped to a low of 5.36 by 2014 . This represented a marked decline in the numbers of users and prescriptions over the study period. The piecewise regression model revealed a significant breakpoint in the last quarter of $2004\left(F_{(3,48)}=337.00\right.$, $P<0.0001)$. In contrast to these findings, among the remaining users, there was an increase in the amount of meperidine per prescription (increase of $0.34 \mathrm{DDDs} /$ prescription/year; $F_{(1,50)}=434$, $P<0.0001, R^{2}=0.89$ ) and the amount of meperidine per user (increase of 1.17 DDDs/user/year; $\left.F_{(1,50)}=653.5, P<0.0001, R^{2}=0.93\right)$.

Conclusion: Following the ISMP warnings, meperidine use dramatically declined. Unfortunately, the remaining users of meperidine are using more meperidine and receiving more meperidine in each prescription. This pattern of results suggests that there may be limits to voluntary safety warnings. Policy action such as removal of medication insurance coverage may represent a logical next step to reverse or de-adopt meperidine and further enhance patient safety.

Keywords: meperidine, pethidine, safety, neurotoxic, utilization

\section{Introduction}

Meperidine (also known as pethidine) was first developed as an anticholinergic agent in 1939, but its analgesic properties were quickly discovered. Meperidine was promoted as an opioid alternative to morphine that might avoid some of morphine's adverse effects including respiratory depression, constipation, urinary retention, abuse, and addiction. ${ }^{1}$ Meperidine became one of the most widely used opioids in North America. ${ }^{2}$ Despite the initial promise and widespread use, it has become clear that meperidine is actually a more problematic drug than morphine. Meperidine's rapid onset, initially 
suggested as an advantage, makes the drug prone to abuse. It is considered one of the most intoxicating opioids and has often been associated with addiction in health care professionals..$^{3,4}$ Meperidine has a relatively short duration of action with a half-life of 2-5 hours, making repeated dosing necessary for continuous pain management. Meperidine is metabolized to normeperidine, a neurotoxic metabolite with a much longer half-life (15-30 hours). Repeated dosing can lead to accumulation of normeperidine and has been associated with seizures and delirium. ${ }^{1}$ Taken on balance, it is generally agreed that meperidine offers few advantages and has considerable additional risks compared to other opioids.

This increased understanding of the limitations of meperidine coupled with case reports of patient harm led safety and quality organizations to begin placing restrictions on its use. ${ }^{5}$ In Canada, the Institute for Safe Medication Practices (ISMP) issued warnings in 2004 and 2005 suggesting that meperidine be avoided, and when used, it should be in limited doses ( $<600 \mathrm{mg} / 24 \mathrm{~h}$ ) and for a limited duration ( $<48$ hours). ${ }^{6,7}$ Many of these restrictions have been implemented in the relatively controlled environment of the hospital. ${ }^{5,8-10}$ There has been relatively limited assessment of the issue of meperidine use in the less regulated community setting. ${ }^{11}$

In this study, the objective was to assess the potential impact of ISMP warnings on prescribing in the community and to determine the current level of usage using time series analysis for the population in Manitoba, Canada (1.3 million people).

\section{Methods}

A longitudinal cross-sectional study using administrative health care data was conducted to examine oral meperidine utilization among persons 16 years of age and older in Manitoba, Canada, between April 1 2001, and March 31, 2014. Prescription data were obtained from the Manitoba Drug Program Information Network database through the Manitoba Centre for Health Policy at the University of Manitoba. Drug Program Information Network is a centralized system used to process outpatient prescriptions in Manitoba. It allows for real-time drug utilization review, and is used to submit claims to the province's universal medication insurance plan (Pharmacare) and to third-party insurers.

Amounts of meperidine are expressed using the World Health Organization method of defined daily doses (DDDs). The DDD value for meperidine is $400 \mathrm{mg}$, the equivalent of a $50 \mathrm{mg}$ tablet taken every 3 hours for a day. The number of meperidine prescriptions, unique users, and total DDDs dispensed overall, and per fiscal quarter of our study period were determined. The numbers of prescriptions and users were expressed per 10,000 persons in the province. We expressed the DDD rate as the total number of DDDs per 1,000 persons, as well as DDDs per prescription, and per user per quarter. All population numbers were calculated using the Manitoba Health Registry data counting only individuals 16 years of age and older.

The mean numbers of DDDs per prescription and per user with their 95\% confidence intervals (CIs) were calculated by fiscal quarter, and a linear regression analysis on these aggregate measures was used to examine the trend over time. The rate of DDDs per 1,000 persons was summarized by fiscal quarter, and the quarterly rates were subject to a piecewise regression analysis to determine if a statistical significant breakpoint was present in the data. This was done by initially using a locally weighted scatter-plot smoother plot to visually determine an estimate of the possible breakpoint. Linear regression was applied to the data before and after this breakpoint separately. The regression results were used to generate initial parameters ( $y$-intercept, slopes for each regression segment, and approximate breakpoint) to enter into our nonlinear regression procedure using the Marquardt method. Autocorrelation was assessed using the DurbinWatson statistic. Data analysis was done using SAS 9.4 (SAS Institute Inc., Cary, NC, USA).

Approval for this study was obtained from the University of Manitoba's Health Research Ethics Board and Manitoba Health's Health Information Privacy Committee.

\section{Results}

Between April 1, 2001 and March 31, 2014, there were 49,063 prescriptions for 442,641 DDDs of oral meperidine dispensed to 9,374 distinct users. The numbers of users and prescriptions changed over time, slightly increasing or plateauing over the first several years before beginning a marked and steady descent starting around 2005 at the time of the ISMP warnings (Figure 1).

The number of DDDs of meperidine dispensed per 1,000 persons in the population closely followed these trends, peaking in the second quarter of 2003 at 11.75 DDDs/1,000 persons, and then dropping to a low of 5.36 DDDs/1,000 persons near the end of the study period (Figure 2). Before using piecewise regression, we first examined the data of DDD per 1,000 persons using simple linear regression. The model fit the data reasonably well, with a Pearson $R^{2}$ value of 0.85 and was statistically significant $\left(F_{(1,50)}=288.7, P<0.001\right)$. A visual examination of a preliminary locally weighted scatter-plot smoother plot revealed an apparent breakpoint in the overall 


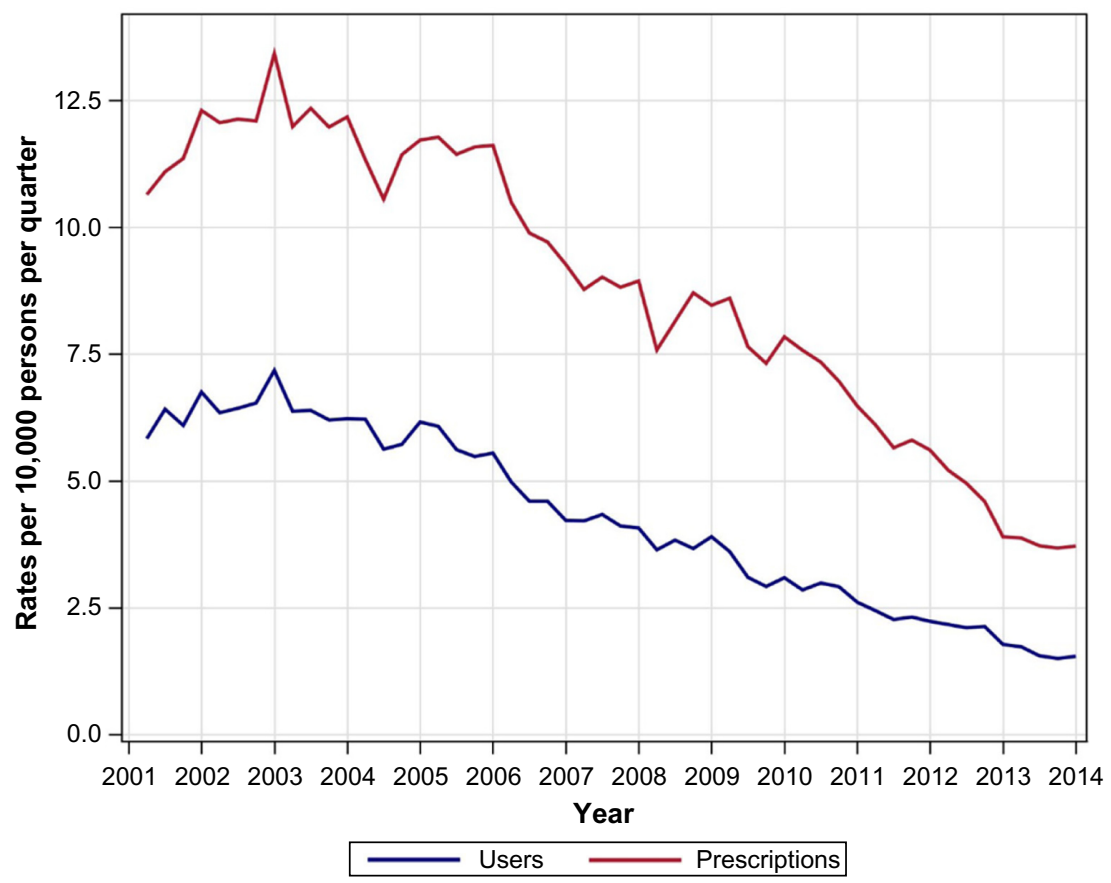

Figure I Meperidine utilization per quarter year in Manitoba.

trend, with a change from a gradual increase or constant value to a steady downward slope. Using an initial breakpoint estimate of January 2005, we applied linear regression to our data in the pre- and post-breakpoint intervals independently. Both regression models were statistically significant; the $R^{2}$ for the first segment was $<0.31(0.3087, P=0.011)$, lower than the single-line model, while the second segment was a better fit, with $R^{2}=0.9961(P<0.0001)$.

The piecewise regression model revealed a significant breakpoint in the last quarter of 2004. The piecewise model

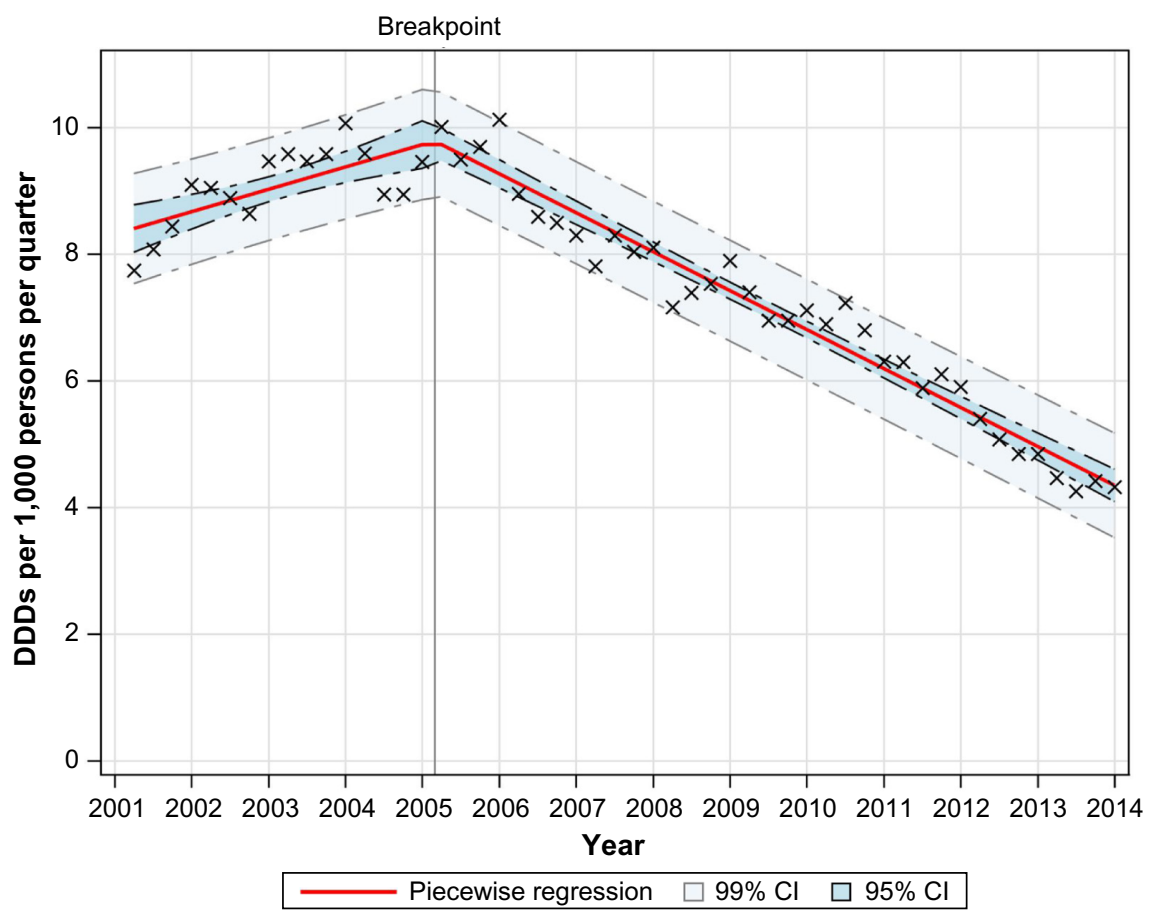

Figure 2 Piecewise regression on DDDs per I,000 persons per quarter. Abbreviations: DDDs, defined daily doses; $\mathrm{Cl}$, confidence interval. 
was a better fit to the data than our initial single linear regression $\left(F_{(3,48)}=337.00, P<0.0001\right.$ compared to $F_{(1,50)}=288.7$, $P<0.001)$. The slope of the initial segment was positive, increasing at $0.28 \mathrm{DDDs} / 1,000 /$ year, and switched to a negative (decreasing) slope at a rate of -0.71 DDDs/1,000/ year (Figure 2).

Due to the common problem of serial autocorrelation with time series data, this was examined in our data, and a significant correlation between adjacent error terms was found (Durbin-Watson $=0.338, P<0.0001$ ). However, after adjusting for autocorrelation in the data, the means square error of our model only changed marginally, from 0.220 to 0.219 , a change of $<0.8 \%$. Therefore, it was concluded that the effect of correlated errors was marginal.

Intensity of use was measured using the number of DDDs per prescription, and per user, summarized by fiscal quarters (Figure 3). Overall, the mean number of DDDs per prescription was 9.02 (95\% CI 8.94, 9.11). The number of DDDs per prescription rose steadily over the study period, starting at a mean of 7.41 DDDs/prescription (95\% CI 7.01, 7.81) in the second quarter of 2001, rising to 11.98 (95\% CI 10.74 , 13.23 ) in the first quarter of 2014, an increase of 4.57 DDDs/ prescription. The results of linear regression on the quarterly means revealed a strong linear trend, with an increase of 0.34 DDDs/prescription/year $\left(F_{(1,50)}=434, P<0.0001, R^{2}=0.89\right)$.
This increase in meperidine per prescription was also reflected in an increase in the amount of meperidine used per person. Overall mean intensity of meperidine use per person was 18.17 DDDs/user/quarter (95\% CI 17.80, 18.54). Intensity changed significantly across the 13 years of our data. The trend in DDDs per user closely followed the trend of DDD per prescription. The rate of DDD per user started at $13.31 \mathrm{DDDs} /$ user/year $(95 \%$ CI $11.59,15.03)$ and rose to 28.07 DDDs/user/year (95\% CI 22.15, 33.98). The results of linear regression on quarterly mean values revealed a strong linear trend, with an increase of 1.17 DDDs/user/year $\left(F_{(1,50)}=653.5, P<0.0001, R^{2}=0.93\right)($ Figure 3$)$.

\section{Discussion}

Given the well-established limitations and safety concerns associated with meperidine, it is reassuring that there has been a dramatic decline in its use. Piecewise regression analysis revealed a breakpoint in the last quarter of 2004. This time corresponds well to the ISMP warnings released in Canada in August 2004. ${ }^{6}$ Likewise, the parallel decline in the number of prescriptions for meperidine and the number of users of meperidine is reassuring. It appears evident that voluntary warnings have been heeded by prescribers and the remaining use of meperidine is limited. These generally downward trends in the overall amount of meperidine use

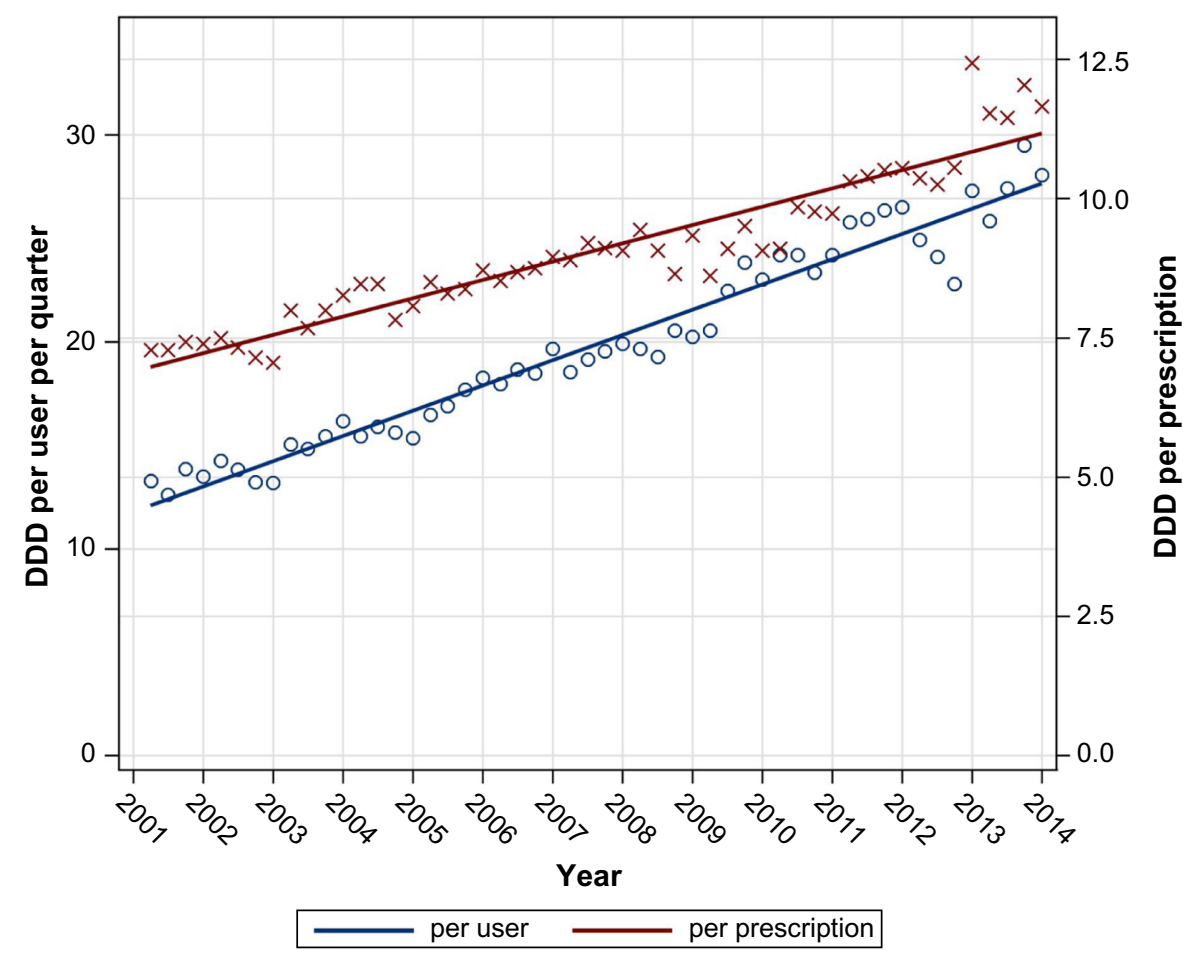

Figure 3 Meperidine DDDs per user and per prescription by quarter year. Abbreviation: DDDs, defined daily doses. 
are in sharp contrast to the changes in the intensity of use per individual user.

DDDs per prescription and DDDs per user per quarter increased linearly throughout the study period. This is concerning and indicates that the remaining users of meperidine are receiving it in high amounts. Safety warnings make it clear that extended use of meperidine is inappropriate and use should be limited to $<48$ hours. ${ }^{6}$ Both DDD per prescription and DDD per user per quarter indicate that the remaining patients are receiving therapy that exceeds the two to three DDDs that would be considered appropriate (Figure 3). The increasing DDDs per prescription and per user represent aggregate average values and may not necessarily reflect new or emerging questionable practice. Rather, as responsive prescribers heed the safety warnings, the remaining use may reveal the patterns of prescribing among prescribers who do not respond to safety warnings.

Fischer et al reviewed opioid analgesic in Canada from 2005 to 2010 using data from selected retail pharmacies. ${ }^{12}$ They found meperidine use ranging for 9-81 DDDs/1,000 population/quarter. Use was declining in most but not all provinces in Canada. Manitoba showed among the lowest rate of meperidine use ( $8 \mathrm{DDDs} / 1,000$ population/quarter) in this cross-Canada survey. Opioid management policies vary across Canada. Manitoba has an electronic networked system that allows all pharmacies to review all prescriptions filled at any pharmacy in the province. Meperidine is covered under the province's Multiple Prescription Program which requires that prescriptions be written on a designated prescription with a copy retained by the prescriber. These systems may be a factor in the lower rate of opioid use generally and meperidine specifically in Manitoba.

In 2010, the highest rates of use were in the provinces of Newfoundland (87 DDDs/1,000 population/quarter) and Nova Scotia (23 DDDs/1,000 population /quarter) or a rate three to eleven times higher than in Manitoba. ${ }^{12}$ In 2007 in Nova Scotia, an effort was made to reduce meperidine use with audit and feedback techniques to educate the small number of prescribers who prescribed the highest amounts of meperidine. ${ }^{11}$ This study made use of Nova Scotia Prescription Monitoring Data that records all prescriptions for controlled drugs filled in community pharmacies from 2005 to 2010 . While a decline was already evident, there was some evidence that the decline of meperidine use was enhanced by this low-cost medication intervention.

There are a number of strengths of this study. It makes use of full population data and captures essentially all meperidine use in the community instead of relying on extrapolation of partial information as done in some past studies. ${ }^{12}$ The study also considers the period of time before and after the 2005 2010 period considered in other Canadian studies. ${ }^{11,12}$ This allows examination of the period prior to the ISMP Canada warnings, so the impact of the warnings can be examined, as well as after 2010 to see if the decline in meperidine has been sustained.

There are also limitations to the study. Information on hospital meperidine was not available and has not been considered in the study. It is however known that hospitals have been very active in reducing meperidine use in the institutional setting. ${ }^{8-10}$ Our study only examined the filling of meperidine prescriptions which is only a surrogate for actual usage which cannot be assessed directly using administrative data. ${ }^{13}$ In the rare case of allergy to other opioids, meperidine may be an appropriate medication choice for short-term use, but no data on opioid allergy was available. Lastly, this observational study provides evidence that the ISMP warning coincides with the decline in meperidine use, but we cannot rule out that other factors may have contributed to this decline. The widespread reporting of meperidine's safety, the activity to restrict hospital meperidine use, and the availability of numerous safer opioid products have all likely contributed to the decline in meperidine use.

In conclusion, following the ISMP warnings, meperidine use in Manitoba dramatically declined. Unfortunately, the remaining users of meperidine are using more meperidine and receiving more meperidine in each prescription. This may be due to a form of depletion of susceptibles, where those prescribers who respond to safety warnings stop using meperidine. This leaves mainly prescribers who are unaware or not concerned with meperidine's safety, who continue to prescribe at well above recommended levels. This pattern of results suggests that voluntary safety warnings may have an important impact on appropriate opioid prescribing but may have limits in their effectiveness. Some prescribers and users may not respond to these voluntary safety warnings. A directed educational approach targeted at the remaining prescribers may be effective, ${ }^{11}$ but consideration could also be given to other policy levers. There are well-established processes to add medications to insurance coverage, but in many jurisdictions, the process to reverse or de-adopt products is much less established. ${ }^{14,15}$ As the safety problems of meperidine have been well established, perhaps it is time to de-adopt meperidine and remove it from coverage under government and private medication insurance programs to provide added incentive to make better mediation choices. 


\section{Acknowledgments}

This study was funded by a University of Manitoba Research Grant. The authors acknowledge the Manitoba Centre for Health Policy for use of data contained in the Population Health Research Data Repository (HIPC File Number 2012/2013-08). The results and conclusions are those of the authors, and no official endorsement by the Manitoba Centre for Health Policy, Manitoba Health, Healthy Living, and Seniors, or other data providers is intended or should be inferred.

An abstract of this paper was presented at the Canadian Association for Population Therapeutics Conference in November 2014 as a poster presentation with interim findings. The actual paper, however, has never been published.

\section{Disclosure}

The authors report no conflicts of interest in this work.

\section{References}

1. Latta KS, Ginsberg B, Barkin RL. Meperidine: a critical review. Am J Ther. 2002;9(1):53-68. doi:10.1097/00045391-200201000-00010.

2. Eisendrath SJ, Goldman B, Douglas J, Dimatteo L, Van Dyke C. Meperidineinduced delirium. Am J Psychiatry. 1987;144(8):1062-1065.

3. Wallot H, Lambert J. Drug addiction among Quebec physicians. Can Med Assoc J. 1982;126(8):927-930. doi:10.1001/jama.237.11.1076b.

4. Walker DJ, Zacny JP. Subjective, psychomotor, and physiological effects of cumulative doses of opioid mu agonists in healthy volunteers. J Pharmacol Exp Ther. 1999;289(3):1454-1464.
5. Gordon DB, Jones HD, Goshman LM, Foley DK, Bland SE. A quality improvement approach to reducing use of meperidine. Jt Comm J Qual Improv. 2000;26(12):686-699.

6. ISMP Canada Safety Bulletin - Meperidine (Demerol $\left.{ }^{\circledR}\right)$ : Issues in Medication Safety; 2004. http://www.ismp-canada.org/download/ safetyBulletins/ISMPCSB2004-08.pdf. Accessed June 1, 2015.

7. Koczmara C, Perri D, Hyland S, Rousseaux L. Meperidine (Demerol) safety issues. Dynamics. 2005;16(1):8-12.

8. Raymo LL, Camejo M, Fudin J. Eradicating analgesic use of meperidine in a hospital. Am J Heal Pharm. 2007;64(11):1150-1152. doi:10.2146/ ajhp060672.

9. Wu MT, Wu TY, Tai YT, Chen HY, Kuo LN. A pharmacist-initiated project to reduce meperidine use in surgical patients. J Exp Clin Med. 2012;4(4):245-248. doi:10.1016/j.jecm.2012.06.002.

10. O'Connor AB, Lang VJ, Quill TE. Eliminating analgesic meperidine use with a supported formulary restriction. Am JMed. 2005;118(8):885-889. doi:10.1016/j.amjmed.2005.01.061.

11. Fisher JE, Zhang Y, Sketris I, Johnston G, Burge F. The effect of an educational intervention on meperidine use in Nova Scotia, Canada: a time series analysis. Pharmacoepidemiol Drug Saf. 2012;21(2):177-183. doi:10.1002/pds.2259.

12. Fischer B, Jones W, Krahn M, Rehm J. Differences and over-time changes in levels of prescription opioid analgesic dispensing from retail pharmacies in Canada, 2005-2010. Pharmacoepidemiol Drug Saf. 2011;20(12):1269-1277. doi:10.1002/pds.2190.

13. Hess LM, Raebel MA, Conner DA, Malone DC. Measurement of adherence in pharmacy administrative databases: a proposal for standard definitions and preferred measures. Ann Pharmacother. 2006;40(7-8): 1280-1288. doi:10.1345/aph.1H018.

14. Prasad V, Vandross A, Toomey C, et al. A decade of reversal: an analysis of 146 contradicted medical practices. Mayo Clin Proc. 2013;88(8):790-798. doi:10.1016/j.mayocp.2013.05.012.

15. Niven DJ, Rubenfeld GD, Kramer AA, Stelfox HT. Effect of published scientific evidence on glycemic control in adult intensive care units. JAMA Intern Med. 2015;175(5):801-809. doi:10.1001/ jamainternmed.2015.0157.
Journal of Pain Research

\section{Publish your work in this journal}

The Journal of Pain Research is an international, peer-reviewed, open access, online journal that welcomes laboratory and clinical findings in the fields of pain research and the prevention and management of pain. Original research, reviews, symposium reports, hypothesis formation and commentaries are all considered for publication.

\section{Dovepress}

The manuscript management system is completely online and includes a very quick and fair peer-review system, which is all easy to use. Visit http://www.dovepress.com/testimonials.php to read real quotes from published authors. 